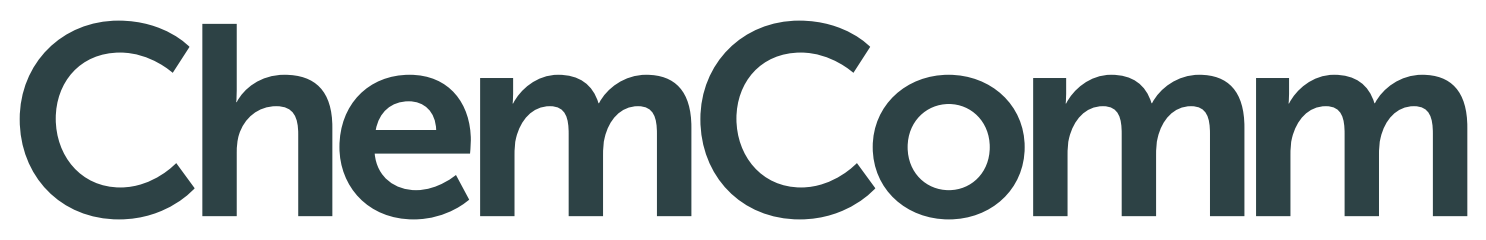

Chemical Communications

www.rsc.org/chemcomm

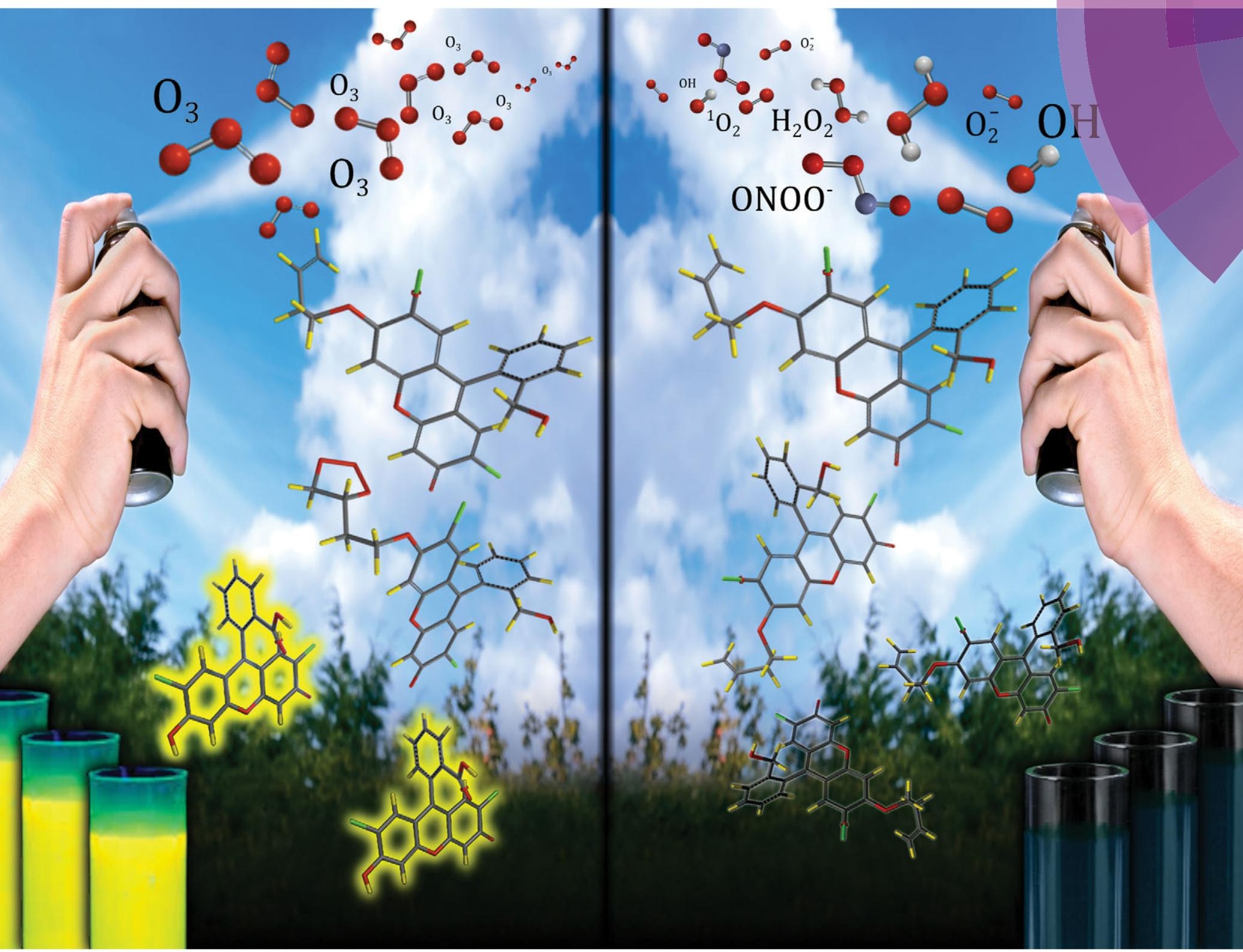

ISSN 1359-7345

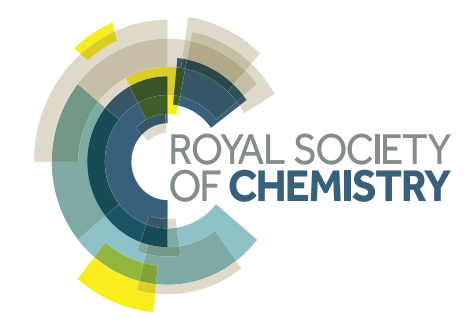




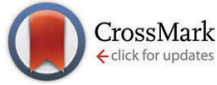

Cite this: Chem. Commun., 2015, 51, 1579

Received 20th October 2014,

Accepted 3rd December 2014

DOI: $10.1039 / \mathrm{c} 4 \mathrm{cc} 08244 \mathrm{c}$

www.rsc.org/chemcomm

\section{Virtues and limitations of Pittsburgh green for ozone detection $\uparrow$}

\author{
Carlos Castelló Beltrán, ${ }^{\mathrm{ab}}$ Elliott A. Palmer, ${ }^{\mathrm{a}}$ Benjamin R. Buckley*a ${ }^{\star \mathrm{a}}$ d Felipe Iza*
}

\begin{abstract}
A recently proposed $2^{\prime}, 7^{\prime}$-dichlorofluorescein (DCF)-derived fluorescent probe for the detection of ozone shows good selectivity against a number of reactive oxygen species and good pH stability for biological and environmental applications. It is found, however, that over oxidation of the fluorescent product (Pittsburgh green) can occur. This could render quantitative measurements inaccurate due to a reduction in fluorescence and overlapping fluorescence signals from over oxidation by-products and it requires careful experimental design. Although difficult to assess by fluorescence measurements, the over oxidation can be conveniently monitored by ${ }^{1} \mathrm{H}$ NMR spectroscopy.
\end{abstract}

The detection and quantification of reactive oxygen species (ROS) has been an area of intense interest due in part to ROS ubiquitous involvement in a range of biological processes. ${ }^{1,2}$ The development of sensitive mechanisms by which to monitor and detect ROS has found wide interest across a range of scientific disciplines. From the range of possible methods of detection, small molecule fluorescent probes have become increasingly applied in the determination and quantification of ROS. This is due to their high levels of sensitivity, simplicity in terms of data collection, and high spatial resolution. ${ }^{3}$ However, one of the major issues surrounding the development of chemical probes for ROS detection revolves around their selectivity. For example, in 1989 Takeuchi and Ibusuki identified ozone in biological samples by chemiluminescence using indigo-5, $5^{\prime}$-disulfonate (IDS, 1; Scheme 1 ). ${ }^{4}$ But it was later found by Wentworth and coworkers that IDS also reacts with singlet oxygen $\left({ }^{1} \mathrm{O}_{2}\right)$ to afford the same product 2 , albeit through an alternative reaction pathway. ${ }^{5}$ With this in mind

\footnotetext{
${ }^{a}$ Department of Chemistry, School of Science, Loughborough University,

Leicestershire,LE113TU, UK. E-mail: b.r.buckley@lboro.ac.uk

${ }^{b}$ School of Electronic, Electrical and Systems Engineering, Loughborough University, Leicestershire, LE11 3TU, UK. E-mail: f.iza@lboro.ac.uk

$\dagger$ Electronic supplementary information (ESI) available: Full experimental details, copies of all ${ }^{1} \mathrm{H}$ and ${ }^{13} \mathrm{C}$ NMR spectra, absorbance and fluorescence data. See DOI: $10.1039 / \mathrm{c} 4 \mathrm{cc} 08244 \mathrm{c}$
}<smiles>[R]OS(=O)(=O)c1ccc2c(c1)C(=O)C(=O)N2</smiles>

Scheme 1 Reaction between IDS 1 and $\mathrm{O}_{3}$.

many research groups active in this area have set out to produce extremely selective probes specific to each type of ROS.

Several ozone probes have been proposed in recent years. For example, a near-infrared fluorescent probe for monitoring ozone in cells has been recently proposed by Tang and coworkers (Trp-Cy, Fig. 1). ${ }^{6}$ They designed the probe using tricarbocyanine (Cy), a near-infrared fluorescent dye, and L-tryptophan (Trp), as an $\mathrm{O}_{3}$ indicator. Trp-Cy and Cy have very different fluorescent excitations at about 630 and $770 \mathrm{~nm}$ respectively and the $\lambda_{\max }$ of the fluorescent emission for Trp-Cy is $770 \mathrm{~nm}$. The difference between the excitation and emission wavelengths avoids interferences, improving the detection sensitivity.

The near-infrared fluorescent probe was tested with different concentrations of ozone and good linearity between the ozone concentration and the fluorescence was observed in the range $0.05-7.0 \mu \mathrm{M}$ of $\mathrm{O}_{3}{ }^{6}{ }^{6} \mathrm{Trp}-\mathrm{Cy}$ was also exposed to chemical species typically encountered in intracellular environments: ROS such as singlet oxygen, hydrogen peroxide and hydroxyl radical; RNS such as nitric oxide; biological antioxidants such as glutathione and ascorbic acid; and metals ions such as $\mathrm{K}^{+}$,

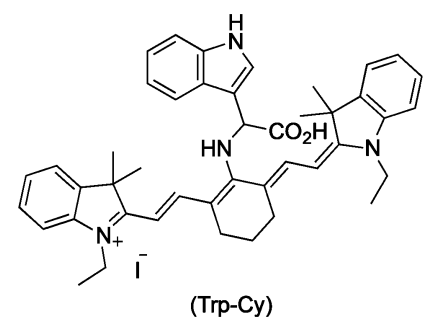

Fig. 1 Trp-Cy ozone detector. 
<smiles></smiles>

Scheme 2 Mechanism of the reaction of the fluorescent probe for ozone synthesised by Garner et al. ${ }^{7,8}$

$\mathrm{Ca}^{2+}$ and $\mathrm{Mg}^{2+}$. The results of these tests showed high selectivity of Trp-Cy towards ozone but the synthesis of the probe is not straight forward and of low yield.

Of simpler synthesis and higher yield is the probe developed by Koide and coworkers for the selective and quantitative detection of ozone (Scheme 2). The probe 3 is derived from $2^{\prime}, 7^{\prime}$-dichlorofluorescein (DCF, 4, Scheme 3) , $^{7,8}$ and works by having a homoallylic group appended to a DCF analogue that is essentially nonflorescent. On addition of ozone, rapid ozonolysis of the double bond proceeds to form $\mathbf{5}$, followed by loss of propenal and liberation of the florescent product 6 (Pittsburgh Green ${ }^{9}$ ). The probe has been used in a variety of biological and non-biological environments. ${ }^{7,8}$

As shown in Fig. 2, the probe has good selectivity against a number of ROS including singlet oxygen, hydrogen peroxide, hydroxyl radical, superoxide, hypochlorite, and peroxynitrite; and the fluorescence is stable over a broad biologically relevant pH range (6-9) (see Fig. 3).

Encouraged by the selectivity and quantitative yield reported in ref. 7 for the probe 3 , we chose to prepare 3 in order to use it

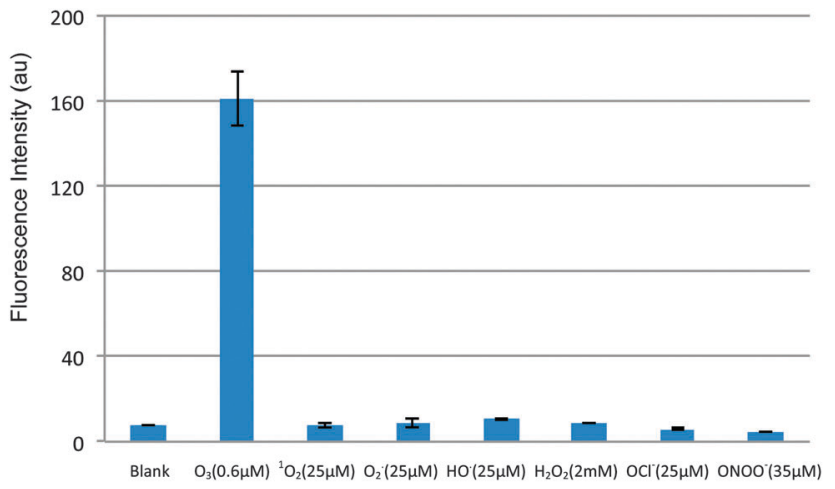

Fig. 2 Selectivity of probe 3 .

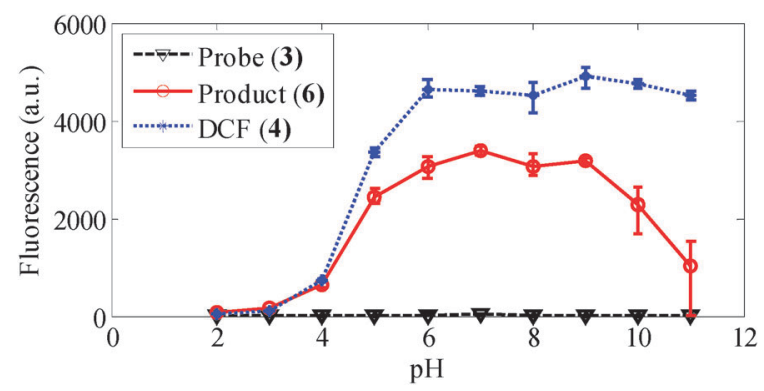

Fig. $3 \mathrm{pH}$ stability of the probe (3), fluorescent product (6) and DCF (4). This agrees with data reported in ref. 9.

in future ozone quantification experiments (Scheme 3). Treatment of the probe 3 using a commercial ozone generator does indeed liberate fluorescent material. The fluorescence, however, changes over time and depends on when it is measured after KI addition (Fig. 4). ${ }^{10}$ This prompted us to analyze the crude isolated reaction mixture and we found that although it had been reported that treatment of the probe under ozonolysis conditions affords the fluorescent compound $\mathbf{6 a}$ in quantitative yield, ${ }^{7}{ }^{1} \mathrm{H}$ NMR

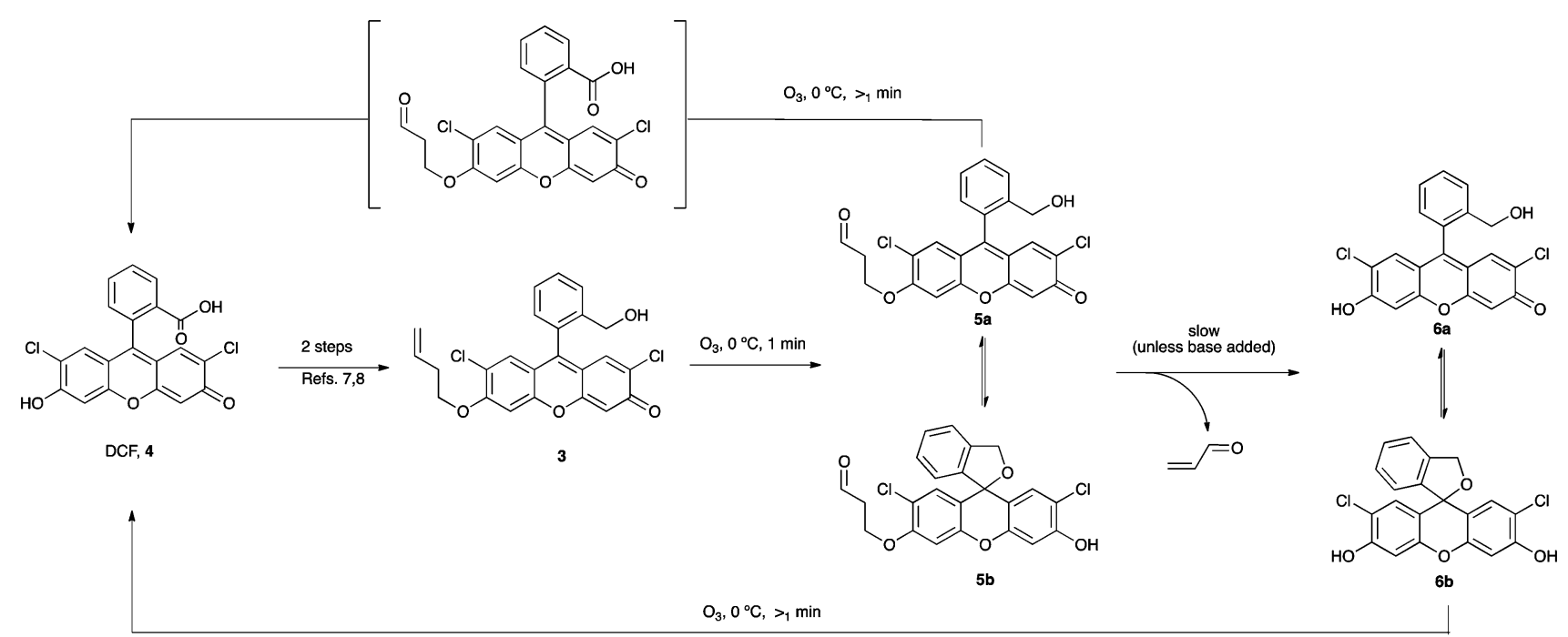

(in situ or from isolated $\mathbf{5 a}, \mathrm{b}$ )

Scheme 3 Synthesis of probe 3 and subsequent reaction products when treated with ozone. 


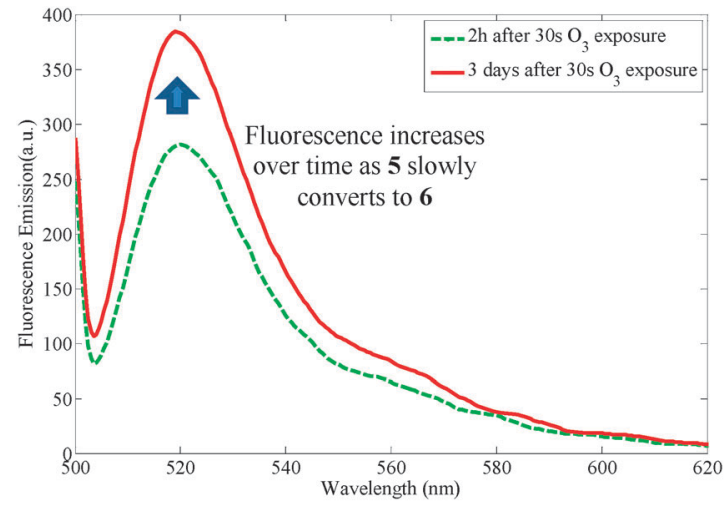

Fig. 4 Observed fluorescence over time after ozone exposure.

spectroscopy questioned its generation (Fig. 5). ${ }^{10}$ Crucially, ref. 7 does not report analytical data of the product and instead it points the reader to an earlier publication in which the authors isolate the compound $6 \mathbf{6}$ and report ${ }^{1} \mathrm{H}$ and ${ }^{13} \mathrm{C}$ NMR data. ${ }^{11}$ This earlier publication, however, deals with the sensing of palladium, hence formation of the fluorescent product is carried out under different conditions than those present in ozonolysis reactions. Further analysis of the crude reaction mixture indicates that both 5 and $\mathbf{6}$ exist as a mixture of ringopened $(\mathbf{5 a} / \mathbf{6 a})$ and ring-closed $(\mathbf{5 b} / \mathbf{6 b})$ materials, and that following the ozonolysis step (and contrary to the assumption made in ref. 7), the side chain is not readily liberated (NMR spectra show that $\mathbf{5 a}, \mathbf{b}$ remain $24 \mathrm{~h}$ after exposure and fluorescence is seen to increase over time, Fig. 4). Addition of $\mathrm{Al}_{2} \mathrm{O}_{3}$ or triethylamine, however, promotes cleavage of the side chain, as shown also in ref. 12. It is noted that the addition needs to be subsequent to the ozone exposure as the presence of the base quenches ozone and prevents the ozonolysis of the probe. Therefore, fluorescent measurements cannot be performed directly in real time.

Finally, it is noted that the fluorescent product and the intermediates (compounds $\mathbf{5 a}, \mathbf{b} / \mathbf{6} \mathbf{6}, \mathbf{b}$ ) undergo oxidation in the presence of ozone, leading to the undesired loss of product 5/6 and the formation of DCF 4 (Scheme 3). Loss of product 6 and subsequent oxidation of DCF accounts for a decrease in fluorescence over increasing $\mathrm{O}_{3}$ exposure time (Fig. 6). ${ }^{4}$

In summary, probe 3 provides a useful means for selective ozone detection across a broad $\mathrm{pH}$ range. If one wished to employ it as a quantitative ozone probe, however, attention needs to be paid to the incomplete cleavage of the side chain and the formation of DCF 4 , especially as DCF 4 and the fluorescent product $\mathbf{6 a}, \mathbf{b}$ have very similar fluorescence spectra. ${ }^{9}$ These limitations can partially be overcome by performing the experiments in an excess of probe 3 , under well-mixed conditions and recording fluorescence at fixed intervals after the

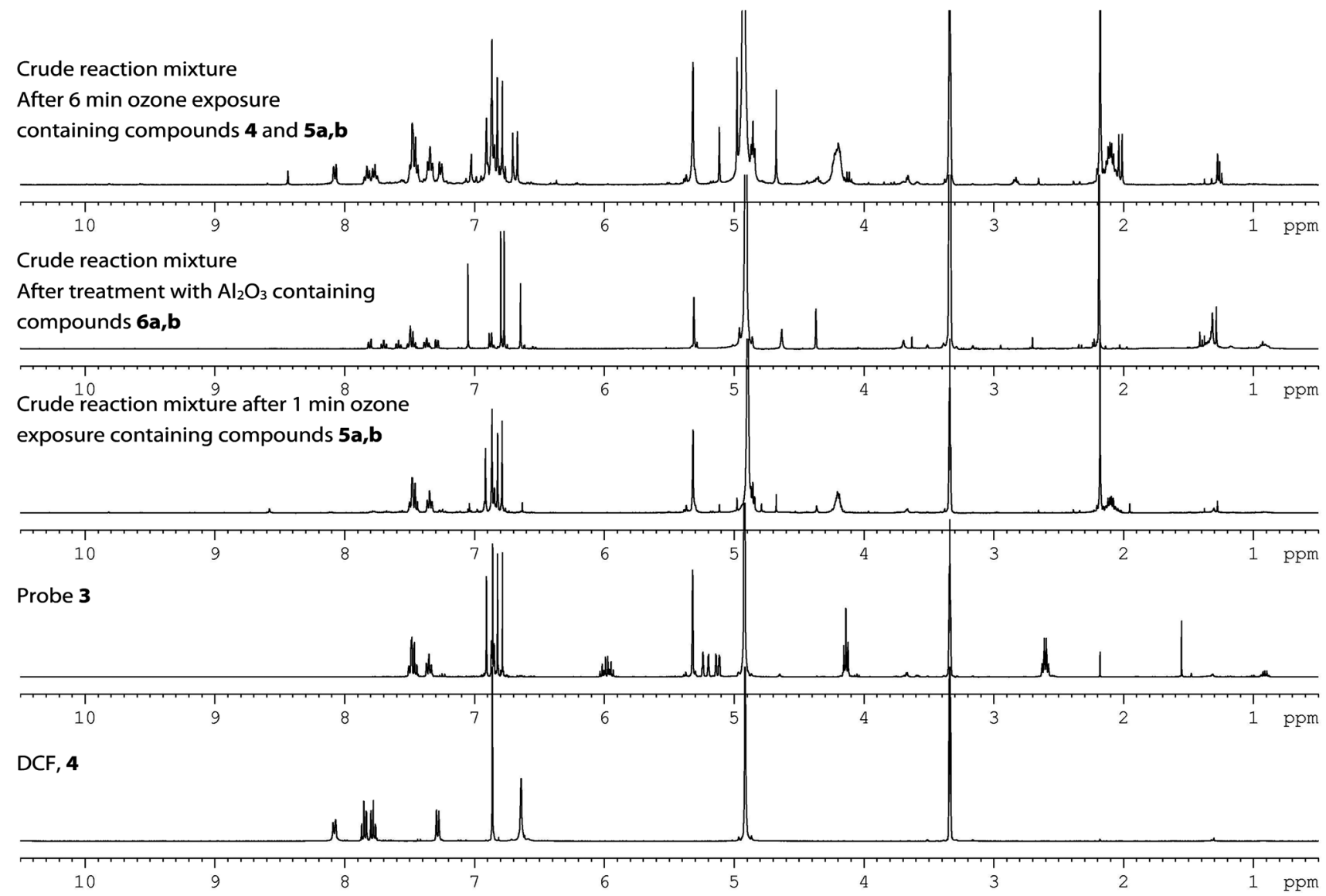

Fig. $5{ }^{1} \mathrm{H}$ NMR spectra of the probe 3 before and after varying treatments of ozone. ${ }^{1} \mathrm{H}$ NMR spectra of authentic DCF 4 for comparison. 


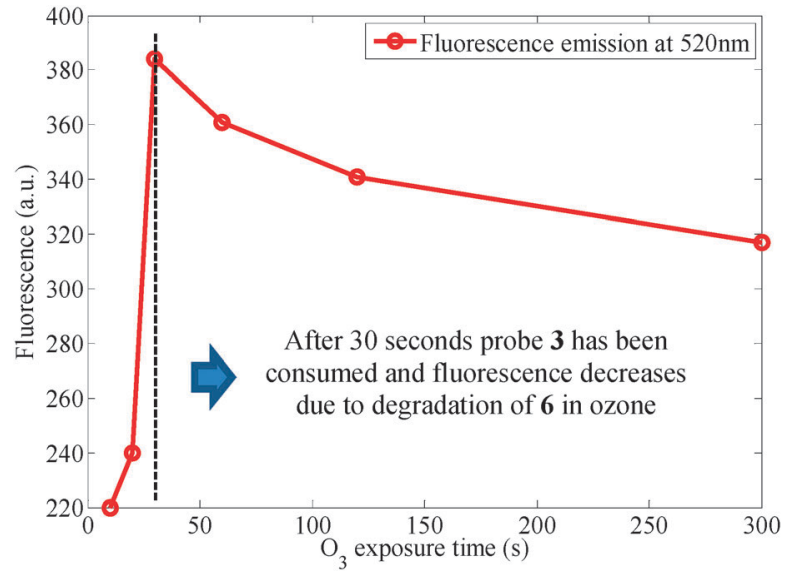

Fig. 6 Observed fluorescence over increased $\mathrm{O}_{3}$ exposure time.

addition (post ozone exposure) of a base to promote the sidechain cleavage.

We thank Loughborough University for a PhD studentship (to C.C.-B.), Research Councils UK for a RCUK Fellowship (to B.R.B.) and the UK Engineering and Physical Science Research Council (F.I.)

\section{Notes and references}

1 X. Chen, X. Tian, I. Shin and J. Yoon, Chem. Soc. Rev., 2011, 40, 4783-4804.

2 M. E. Jun, B. Roy and K. H. Ahn, Chem. Commun., 2011, 47, 7583-7601.

3 P. Wardman, Free Radical Biol. Med., 2007, 43, 995-1022.

4 K. Takeuchi and T. Ibusuki, Anal. Chem., 1989, 61, 619-623.

5 P. Wentworth, J. E. McDunn, A. D. Wentworth, C. Takeuchi, J. Nieva, T. Jones, C. Bautista, J. M. Ruedi, A. Gutierrez, K. D. Janda, B. M. Babior, A. Eschenmoser and R. A. Lerner, Science, 2002, 298, 2195-2199.

6 K. Xu, S. Sun, J. Li, L. Li, M. Qiang and B. Tang, Chem. Commun., 2012, 48, 684-686.

7 A. L. Garner, C. M. St Croix, B. R. Pitt, G. D. Leikauf, S. Ando and K. Koide, Nat. Chem., 2009, 1, 316-321.

8 A. L. Garner, C. M. St Croix, B. R. Pitt, G. D. Leikauf, S. Ando and K. Koide, Nat. Chem., 2010, $2,422$.

9 K. Koide, F. Song, D. D. E. Groh, A. L. Garner, V. D. Mitchell, L. A. Davidson and N. A. Hukriede, ChemBioChem, 2007, 9, 214-218.

10 In order to check our findings were not due to a problem with the source of ozone, two ozone generators from different suppliers were employed and similar results were obtained with both devices. See ESI $\dagger$ for details.

11 F. Song, A. L. Garner and K. Koide, J. Am. Chem. Soc., 2007, 129, 12354-12355.

12 K. L. Leslie, D. Li and K. Koide, J. Org. Chem., 2011, 76, 6860-6865. 